\title{
Challenges and Opportunities in Rural Nursing Preceptorship: What Multimedia Participant Action Reveals (Défis et possibilités du préceptorat infırmier en milieu rural : ce qu'une participation multimédia révèle)
}

Olive Yonge

University of Alberta, oyonge@ualberta.ca

Florence L. Luhanga

University of Regina, florence.luhanga@uregina.ca

Vicki C. Foley

University of Prince Edward Island, vfoley@upei.ca

Deirdre M. Jackman

University of Alberta, deirdre.jackman@ualberta.ca

Florence Myrick

University of Alberta, amyrick@ualberta.ca

Tracy Oosterbroek

University of Alberta, oosterbr@ualberta.ca

Follow this and additional works at: https://qane-afi.casn.ca/journal

Part of the Educational Methods Commons, Higher Education and Teaching Commons, and the Public Health and Community Nursing Commons

\section{Recommended Citation}

Yonge, Olive; Luhanga, Florence L.; Foley, Vicki C.; Jackman, Deirdre M.; Myrick, Florence; and Oosterbroek, Tracy (2018) "Challenges and Opportunities in Rural Nursing Preceptorship: What Multimedia Participant Action Reveals (Défis et possibilités du préceptorat infirmier en milieu rural : ce qu'une participation multimédia révèle)," Quality Advancement in Nursing Education - Avancées en formation infirmière: Vol. 4: Iss. 1, Article 7.

DOI: https://doi.org/10.17483/2368-6669.1130

This Article is brought to you for free and open access by Quality Advancement in Nursing Education - Avancées en formation infirmière. It has been accepted for inclusion in Quality Advancement in Nursing Education - Avancées en formation infirmière by an authorized editor of Quality Advancement in Nursing Education - Avancées en formation infirmière. 


\section{Challenges and Opportunities in Rural Nursing Preceptorship: What Multimedia Participant Action Reveals (Défis et possibilités du préceptorat infirmier en milieu rural : ce qu'une participation multimédia révèle)}

\section{Cover Page Footnote}

This study was funded by the Office of the Provost and Vice President (Academic), University of Alberta. Acknowledgements to research assistants Jim Cockell, Kyra Cusveller, Samantha Marks and Grace Miazga Cette étude a bénéficié du financement du bureau du recteur et vice-recteur aux études de I'University of Alberta. Nous remercions I les assistants de recherche : Jim Cockell, Kyra Cusveller, Samantha Marks et Grace Miazga. 
In an increasingly multimedia-driven information economy, stakeholders in rural nursing require innovative messaging to recruit potential nurses and reach educators, policymakers, and the general public. The firsthand perspectives of those involved in rural, clinical teaching and learning are vital to such messaging, insofar as rural placements are a primary means of drawing new nurses to these critically understaffed regions (Amundson, Moulton, Zimmerman, \& Johnson, 2008; Charles, Bainbridge, Copeman-Stewart, Art, \& Kassam, 2006; Shannon et al., 2006; Yonge et al., 2011b). For this study, the researchers employed principles of participatory action research (PAR) using digital multimedia. The central elements of PAR are (a) cyclical data collection, analysis, and action, wherein researchers and participants are constantly reflexive about their roles in these processes; (b) delegation of researcher prerogatives - such as study focus and priorities - to participants, thereby creating a more democratic research environment; and (c) alignment of research outcomes with the priorities and goals expressed by participants (Baum, MacDougall, \& Smith, 2006, p. 854). The purpose of the current study was to give participating rural nurses and their students the power to directly tell their own stories about rural preceptorship, using photovoice and digital storytelling. This article explores challenges and opportunities arising from these stories, as well as the power of digital technology in mediating participants' experiences and yielding innovative research output.

\section{Background}

For the purposes of health care, a community can be considered rural if it is at least $80 \mathrm{~km}$ distant from a major regional health care centre, and its population does not exceed 10000 (Van Hofwegen, Kirkham, \& Harwood, 2005). The terms suburban and semi-rural, both employed below, respectively refer to communities that fall between 40 and $80 \mathrm{~km}$ from a major regional health care centre, and communities with populations between 10000 and 20000 . The existing literature on rural clinical teaching and learning points to benefits such as personal and professional enrichment for practising nurses who teach, and interprofessional experience, holistic perspective, generalist coverage, and multiple sources of feedback for students. Challenges for preceptors include balancing teaching duties with a full-time workload and maintaining professional boundaries with students; for the latter, primary challenges are isolation and lack of familiarity with the rural context, particularly the dissonance of encountering rural community ethos and health care seeking behaviours for the first time.

Rural preceptorship outcomes can significantly influence the willingness both of students to consider rural careers and of rural preceptors to undertake future preceptorships (Yonge, 2009). Clinical supervision - whether formal preceptorship or informal mentorship - affords students/novices and preceptors/mentors the opportunity to evolve together, as the former acquire practice confidence and skills while the latter are able to reflect on, challenge, and improve their own routines as they engage in teaching (Charles et al., 2006; Mills, Francis, \& Bonner, 2008; Shannon et al., 2006; Yonge, Myrick, Ferguson, \& Grundy, 2013a). This process is especially pertinent to rural practice, in which nurses' opportunities for professional development and ongoing education are limited by distance. In a mentorship study, Gibb, Anderson, and Forsyth (2004) found rural workplaces provided the opportunity to develop life skills, such as teaching and learning competencies, in addition to clinical skills. Through teaching, rural nurses can derive personal satisfaction from the promotion and propagation of rural health care values and practices (Shannon et al., 2006). As generalists working in understaffed locations, however, rural preceptors may struggle to keep abreast of their workload as they uphold their teaching commitments (Bratt, 2009; Keahey, 2008; Shannon et al., 2006). 
When preceptors' workloads are inordinately heavy, their students' learning goals are compromised (Pront, Kelton, Munt, \& Hutton, 2013; Zournazis \& Marlow, 2015).

Some of the most conspicuous challenges in rural preceptorship involve relationships, as informality and boundary crossing are more common in rural communities and health care settings as compared with urban settings. Rural nurses teach students and novice nurses how to negotiate boundaries and reciprocity when dealing with clients (Mills, Francis, \& Bonner, 2007; Yonge, Myrick, Ferguson, \& Grundy, 2015); however, the relational bond between preceptors and students may also entail boundary crossings, such as personal disclosure, gift exchanges, touching, and post-preceptorship contact (Yonge, 2009). Indeed, the absence of such interpersonal gestures can be detrimental to learning outcomes, as students feel intimidated or obliged to spend time managing the relationship (Pront et al., 2013). Positive preceptorship outcomes are thus dependent on appropriate professional boundaries (Yonge, 2007, 2009). Personal enmeshment with preceptors and other staff can leave students open to exploitation as auxiliary, unpaid help in short-staffed rural health care settings (Pront et al., 2013; Sedgwick \& Rougeau, 2010; Yonge, Myrick, Ferguson, \& Grundy, 2013b). Blurred boundaries may compromise a preceptor's ability to objectively evaluate a student upon conclusion of the preceptorship (Yonge, 2007; Yonge, Myrick, \& Ferguson, 2011a).

Yonge, Ferguson, and Myrick (2006) found that preceptors and students felt most challenged by isolation (especially from faculty), weather events, unpredictable patient loads, and lack of resources; these participants most valued the informal community ethos, ample time together, a holistic perspective, variety of practice opportunities, and interprofessional (IP) teamwork. These findings have been borne out repeatedly over a decade of subsequent research by the authors and others. Rural preceptors and students capitalize on road trips to client homes, for instance, to share feedback and build rapport (Yonge et al., 2011a). Rural settings are now widely acknowledged as ideal sites to learn IP teamwork (Amundsen et al., 2008; Charles et al., 2006; MacDowell, Glasser, Weidenbacher-Hoper, \& Peters, 2014). Students benefit from the informal, IP team ethos of rural settings as they receive guidance and feedback from team members other than their preceptors (Sedgwick, 2011; Yonge, 2009; Yonge et al., 2013b). However, students may still struggle to navigate the social order of a rural health care site to achieve a sense of belonging. Such a process may depend as much on aptitude as on preparation (Sedgwick \& Rougeau, 2010). The quantity and quality of students' rural IP team experiences can be dependent on their preceptors' time management and communication skills (Sedgwick, 2011). Disengagement of faculty, owing to distance and lack of familiarity with the rural context, may introduce doubt into preceptors' evaluations and the validity of final grades, and subsequently compromise the students' psychosocial wellness (Luhanga, Dickieson, \& Mossey, 2010; Yonge et al., 2013b).

Rural preceptorships enable nursing students to achieve a holistic grasp of health, community, and landscape (Amundson et al., 2008; Charles et al., 2006; Yonge, Myrick, Ferguson, \& Grundy, 2013c), but students may initially struggle with the competing values of community and society (Presley, 2013; Yonge et al., 2013c, 2015), or of nursing theory versus frontline practice (Dowdle-Simons, 2013). Sedgwick and Yonge (2008) found, for example, that students felt most challenged by the psychosocial and psychomotor demands of the rural practice setting, for which their classroom studies had not fully prepared them. As well, students contended with rural clients' distrust of outsiders, health seeking behaviours, and understanding of diagnoses (Presley, 2013). 
In summary, the challenges and opportunities of rural preceptorship are broadly apparent from the existing literature, but pulling them into coherent and compelling narratives - suitable for the era of user-generated content and Web 2.0 - is a vital endeavour for recruitment. Nurse educators and other rural stakeholders need innovative, firsthand messaging to show how the benefits of a rural clinical education offset-and indeed accrue from-its hardships. The researchers sought to address this deficit with the current, multimedia PAR project.

\section{Methods}

\section{Aims}

The study was designed to address the primary research question, "What are the opportunities and challenges of a rural nursing preceptorship?" by actively engaging participants in qualitative data collection, analysis, and authorship of project output. The researchers also sought to examine how participants reify their experiences through digital media, and how the research process and outcomes might serve to empower these participants.

\section{Design}

Digital technology can potentially revolutionize participant action, given the increasing ubiquity of personal devices and user-generated content in participants' daily routines-a defining feature of Web 2.0 (Gazarian, 2010). A number of studies have established that multimodal, digital participant action-particularly when it incorporates visual methods such as digital photography and digital storytelling-mobilizes and transforms the reflexive, discursive stage of the PAR process (Fenton, 2014; Gubrium \& Harper, 2013; Otañez \& Guerrero, 2015; Wilson \& Flicker, 2015).

Each phase of the project — data collection, thematic analysis, and authorship of outputwas conceived with participant action and collaboration foremost in mind. The dataset comprised participants' digital photographs, as well as recordings and transcripts of interviews wherein they explained their images and the issues underlying them-a process known as photovoice (Wang $\&$ Burris, 1997). The discussions yielded a series of categories which, in turn, informed thematic analysis carried out with participant corroboration and legitimation. The findings were presented in online, digital stories: brief videos comprising still images, narration, text, underscoring, and other media.

\section{Ethical considerations}

Prior to project implementation, the researchers sought the approval of (a) the human research ethics board at their place of employment, (b) the health authorities overseeing all sites where data collection was to take place, and (c) local site managers whose staff and students were targeted for recruitment as participants. All individuals taking part, or depicted within the data, provided signed, informed consent to that effect. The researchers advised all prospective participants about potential benefits and risks in the study, emphasizing that withdrawal was optional at any stage, without academic or professional consequences. The study proposal and participant orientations explicitly precluded the collection or use of patient data.

\section{Participants}

Participants were recruited through purposive and snowball sampling, described below. Through a faculty coordinator at a baccalaureate nursing program in western Canada, the researchers recruited seven senior (final year), female students, all of whom had chosen rural, 
semi-rural or suburban placements for their final preceptorships, and five acute care registered nurses (RNs), one male and four female, assigned to precept these students at seven sites. Two further preceptors declined to participate. Owing to the limited cohort of students choosing nonurban preceptorship placements, no exclusion criteria were warranted. The preceptors' years of practice experience ranged from seven to 28 years, all of whom had prior experience in preceptorship. The seven sites contained 10 to 76 beds, serving populations between 800 and 18 000. From the nursing faculty, the closest community was $42 \mathrm{~km}$, the furthest $416 \mathrm{~km}$.

Orientation to the project for individual students was conducted on campus, while preceptors and their colleagues were oriented onsite. These 60-90 minute sessions, carried out by the principal investigator, introduced participants to digital photography basics and the ethics of data collection. All participants $(n=12)$ were instructed to photograph any aspects of the landscape, community, or acute care site (barring patients) representing opportunities or challenges of rural nursing preceptorship, and to obtain a signed consent form and photographic release from any individuals they photographed.

\section{Data collection and analysis}

Participants collected data according to a two-stage plan: 1) five weeks of acclimatization and comprehensive, photographic exploration of the setting, and 2) five weeks of sharpened focus on topics and questions arising from the first stage of data collection. Each stage culminated in an onsite discussion (recorded and transcribed), wherein the researchers used participants' photographs to elicit their experiences and insights regarding challenges and opportunities.

Data coding began as soon as the first stage was completed. Through open coding, data were gathered into nodes (or categories) based on issues or themes that became apparent in participants' remarks. Google Docs provided the researchers a forum to mutually determine and sharpen these categories. One member of the research team carried out coding independently using NVivo10, thereby corroborating the group codes. Once the data were saturated, open coding was succeeded by theoretical coding, whereby the researchers constructed and tested theories to rationalize patterns in the dataset. On the basis of these findings, the researchers organized a digital storytelling initiative in which they sought the participants' collaborative authorship.

\section{Validation}

To corroborate and legitimate the thematic analysis (Feredey \& Muir-Cochrane, 2006, p. 7), the researchers presented their findings to participants via a PowerPoint slideshow. Participants were also given the opportunity to tell their own stories, using their own data, through the digital storytelling initiative. Through these measures, the researchers were able to triangulate their analysis among multiple participants, who replicated (verified) the findings internally by confirming or elaborating on their own data and externally by corroborating the data of other participants.

\section{Findings}

The participants in this study provided 442 digital photographs and 11 hours of recorded commentary. The study design - photovoice data collection, collaborative thematic analysis and digital storytelling-yielded a novel way of conceptualizing rural clinical education, namely, rural clinical placements teach nursing students to recognize and capitalize on opportunities, 
while accepting and managing challenges. The participants validated this central theme and the findings it comprised, as discussed below. Challenges were concrete and thus manifestly apparent through photographic data, while opportunities were abstract, emerging from participant interviews and focused questioning. The findings applied both to rural and to semirural/suburban health care sites included in the study. Only the digital storytelling initiative proved challenging, inasmuch as all but two participants (both students) declined to commit any additional time to authoring a digital story. The researchers carried out this initiative ${ }^{1}$ nonetheless, thereby creating an additional means by which to solicit participant feedback and deliver the project findings to a wider audience.

\section{"You Do What You Can"}

The students, having recently undergone clinical rotations in large urban acute care settings, were initially taken aback by the deficits they encountered in rural resources and supplies. Tiffany (student) photographed the amount of paperwork confronting her and her preceptor, owing to the absence of clerical support during the evenings. She remarked:

The nurses know how to use the programs that the unit clerks do, to put in the tests, to order lab work - it's a lot of work. The extra things you have to do when you work in a rural setting... can be challenging for a student who's already trying to just do what a nurse in the city does.

In a revealing instance of metadata, her preceptor declined to take part in the study, citing the formidable workload. Anna, who precepted at another setting, expressed her frustration at administrative "work functions that I have to do, but really aren't any learning for [my student]."

The students struggled most in coming to grips with the lack of human resources. This finding was evident especially when the clinical sites were at capacity and casual relief was in short supply. "It's hard to retain casual staff here, "cause they would rather be elsewhere," acknowledged Shirley (preceptor). "Some of the new girls, they're from [the city]... so in all likelihood, if they get a job somewhere else one day, they'll probably leave our casual pool too." This observation served to underscore the cyclical nature of the provincial economy; an economic downturn might temporarily increase the number of new nurses seeking casual employment outside the city, but the staff had no illusions about retaining them. Other services and staff, which the students had come to take for granted in their urban rotations, were limited or nonexistent. "You can't just send blood work to the lab or get an X-ray at 2 am," remarked Tiffany, who photographed a notice to this effect (Figure 1). "You have to call for emergencies. The X-ray tech is on-call, and lab is on-call, and it's just the two nurses... we don't have everything a normal lab has; we can't do all the tests." Alissa (student) pointed out that the absence of specializations directly impacted the staff nurses: "Out here, you don't have all the disciplines; you don't have a respiratory tech, you don't have an IV team, you don't have all the specialties; so it's a bit challenging."

\footnotetext{
${ }^{1}$ Viewable at https://www.ualberta.ca/nursing/research/research-units/rural-preceptorship
} 


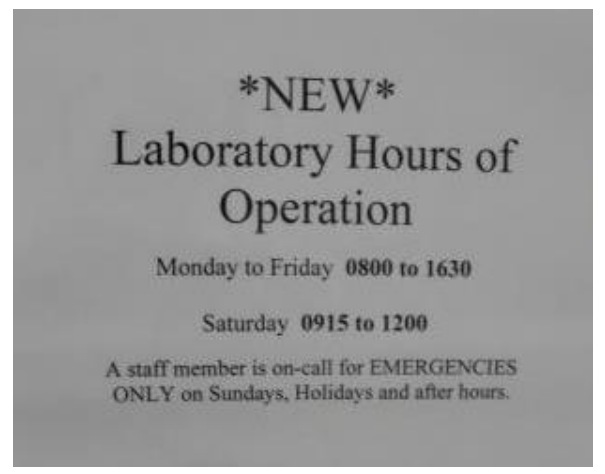

Figure 1. Notice of laboratory hours in rural care setting, as photographed by a student

The preceptors themselves were not unaware of the challenges they faced, having been educated in urban settings and, in one case, filling casual shifts at an urban hospital $65 \mathrm{~km}$ away. Even for those nurses who rarely set foot in an urban hospital, a reminder of their disadvantages was only as distant as the air ambulance. Observing her student's photograph of a ventilator onsite (Figure 2), Janet (preceptor) commented, "It's so archaic, it's probably from the 1970s. Honestly, you wouldn't want to be using it." Her student Alissa added, "And then STARS [Shock Trauma Air Rescue Service] comes with their [new] blood gas machine."

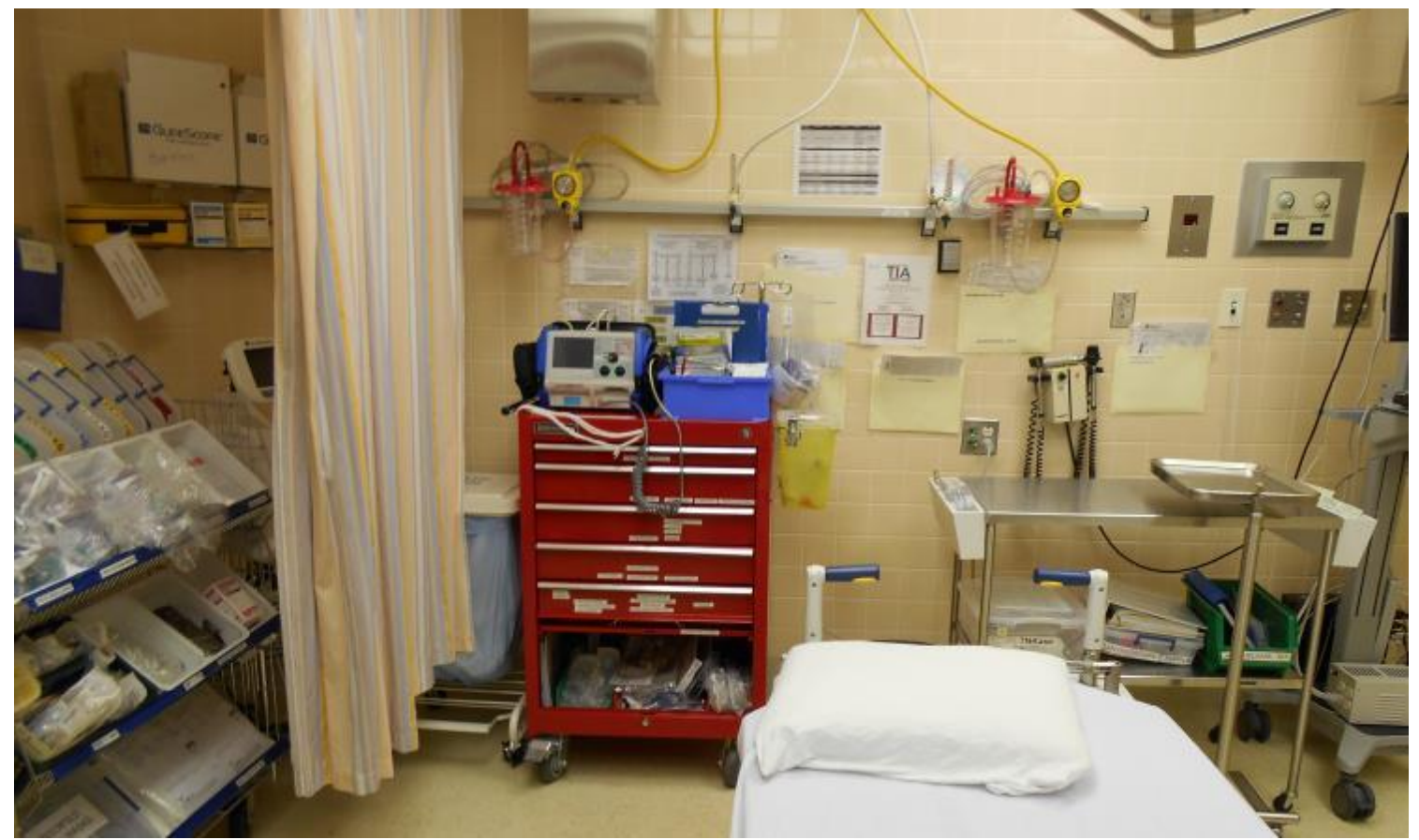

Figure 2. Onsite ventilator in rural care setting, as photographed by a student

The rural nurse preceptors had become accustomed to making do, but they did not lack for standards of comparison as to how their facilities came up short. "One of the nurses told me to take this photo just to represent [how] she's sort of frustrated because a lot of the equipment is quite old here," said Tiffany.

While three of the health care sites studied were nominally suburban or semi-rural, falling within $80 \mathrm{~km}$ of a major urban hospital and/or serving populations greater than 10000 (Van Hofwegen, Kirkham, \& Harwood, 2005), they nonetheless corroborated the data from smaller 
and more distant sites. Rhonda, a suburban nurse who also worked in the city, compared her circumstances to nursing in the Arctic:

You might as well pretend you're just as isolated, 'cause you never know when Neonatal Intensive Care Unit (NICU) can get to you; if you can STARS somebody out; if you can do anything. [If] somebody comes in here 33 weeks and they're $6 \mathrm{~cm}$ [dilated], they're not gonna go nowhere, so there's no point you panicking, getting all upset. It's like, $O K$, I'm in Inuvik and my nearest help is... gonna be 8 hours, and you just go from there. You do what you can.

Rhonda introduced her student to the reality that northern prairie weather events are occasionally severe enough to restrict access by road and air, isolating suburban hospitals as thoroughly as remote outposts. "You really have to have skills and know how to stabilize patients," agreed Kendra, a student at another site. "One night... [STARS] wouldn't come because it was unsafe to travel." Living and working on the Canadian prairies, suburban, semirural, and rural nurses had to be equally level-headed, independent, and resourceful; technicalities of demographics and distance had no bearing on the challenges they faced.

From the students' perspective, most of the challenges they encountered also represented opportunities to acquire knowledge. Lack of materials, for instance, meant learning "not to be as wasteful and just make sure that I'm using only what I need." Lack of clerical support meant "more opportunity for learning because you are exposed to every aspect of office work." The obligation to generalize, in the absence of discrete units and specializations, meant "you got to experience a wide variety of patients" and experience being "a jack of all trades." Making a virtue of necessity, in other words, was a central precept of the rural clinical experience that most students grasped from the outset. And as Murray (preceptor) pointed out, such learning carried on into professional practice, whether rural or urban:

We try to [give] the best possible care for our patients, [and] that's the only way we can do it: make challenges [into] an opportunity to develop... I always think of nursing as a progressing profession, it's not a one-stop profession... Health care is always developing; it's always an opportunity.

\section{"It Made It More New and Fresh"}

Beyond the realm of clinical skills and knowledge acquisition, the students discovered unexpected opportunities for holistic insight, psychosocial wellness, and personal growth. Kendra undertook her preceptorship in the small town where she grew up, following an absence of 10 years. She spoke of how the experience transformed her perceptions of the entire landscape, right down to mundane objects such as hay bales (Figure 3): "Before, I always saw [them] as something that you play on. Now I look at [them] as determinants of health... farming accidents, kids playing on hay bales [and] falling off..." Kendra's preceptorship resonated not only educationally but also personally and emotionally, as she gained a new pride in her own background. "At first I thought, where I grew up, it's not really anything special. This changed it all; it made it more new and fresh." Not coincidentally, she was one of the participants who actively took part in the digital storytelling phase of the project. 


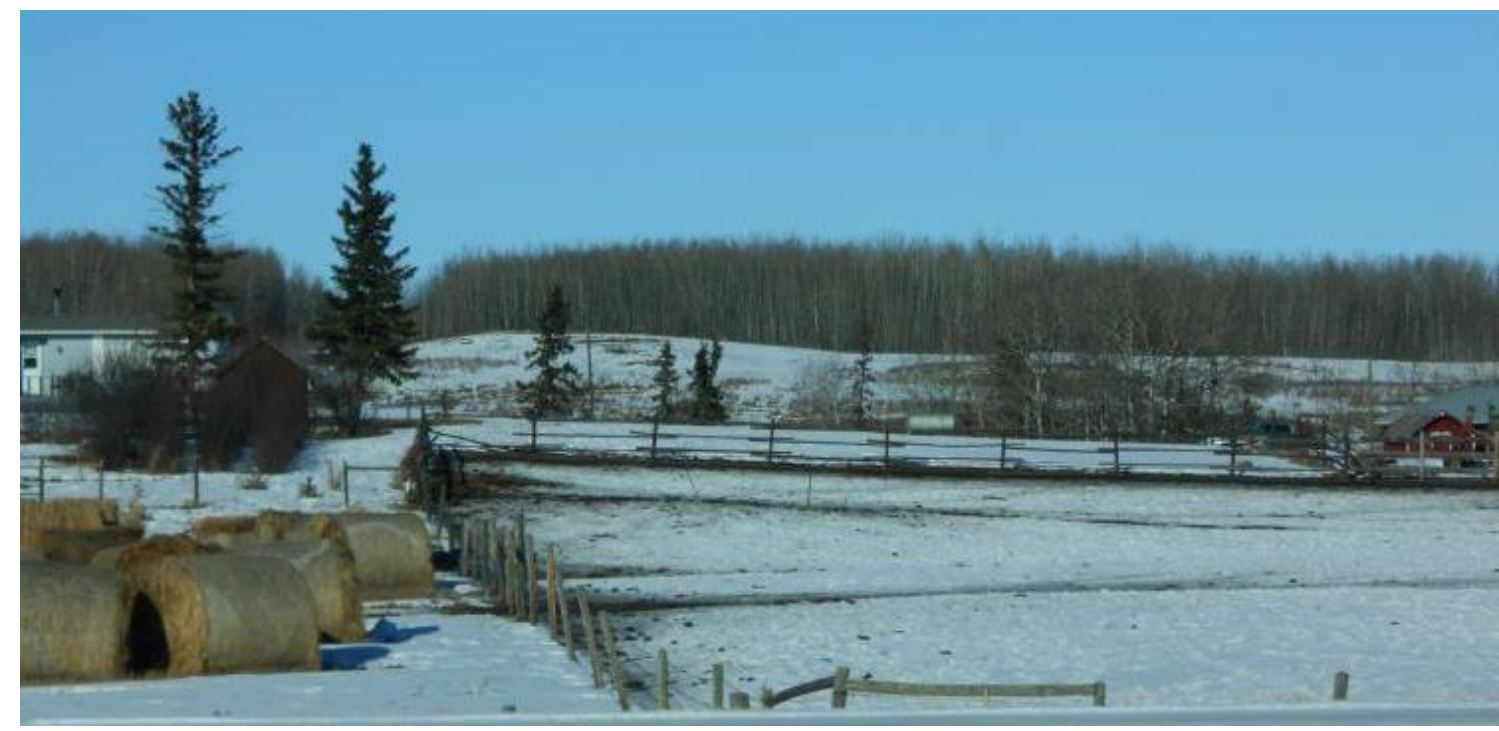

Figure 3. Hay bales as determinants of health, as photographed by a student

Rural preceptorship enabled the students to take part in a community ethos that extended well beyond the confines of the clinical setting. Kendra touched on this in her childhood recollections:

My grandpa was driving people who had hospital appointments to the city. He'd ask them to pay whatever they could. He'd go to the hospital or wherever and just say, "Anybody need a ride to the city today, for an appointment?"

Community voluntarism often made the difference between adequate and truly compassionate care, such as the outpouring of support in instances of tragedy. "For our fetal demises, we have a lady that gets wedding dresses given to her and she... makes them into little gowns for them," said Rhonda (preceptor), "[and the] funeral home in town here will do all of the funeral arrangements for free."

Such gestures were reciprocated by hospital staff, who gave of their own time and energy to ensure their clients would receive the best possible care. Tiffany (student) was especially impressed by the efforts of a doctor and nurse, who ran marathons to raise funds for a new ultrasound machine (Figure 4). Reciprocal voluntarism and gift giving, between the caregivers and community, demonstrated to the students how personal and professional boundaries were negotiable, and how rural caregiving amounted not just to a career but to a personal stake in the community. "Some of the staff on this unit... go to our [palliative] patients' funerals," said Shirley (preceptor). Boundaries and confidentiality with the public could also be problematic, however. As Alissa (student) observed:

[When] somebody passes away, one of the nurses is like, "I got a text from my grandparents saying Oh, I hear so-and-so passed away," and she's like, "I'm not even done my shift; how do you know that? That was an hour ago!"

Rural community members pulled together to support one another as family, friends, and neighbours, but the occasional, challenging by-products of these community bonds were intrusiveness and gossip. 


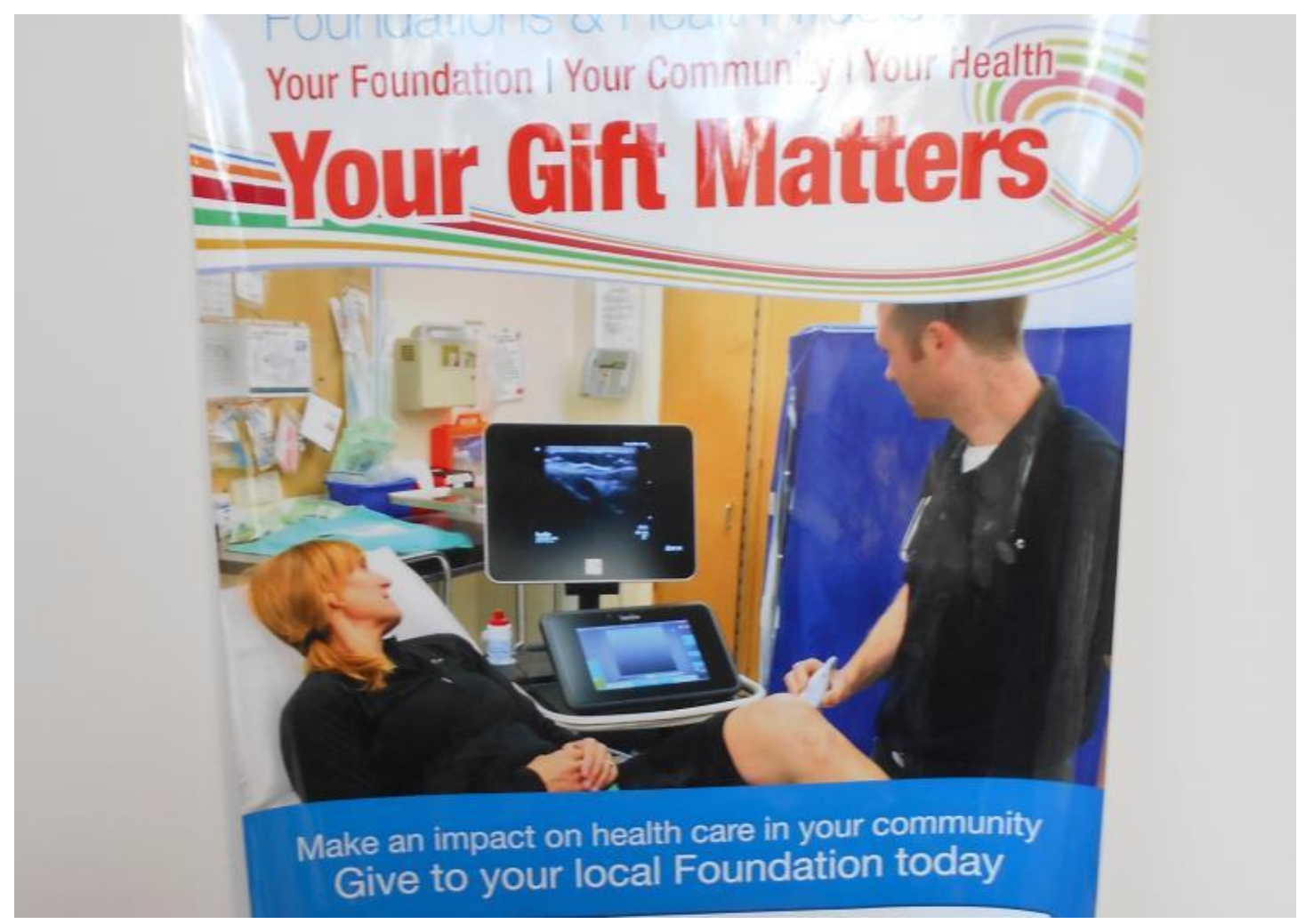

Figure 4. Photo of fundraiser for rural care setting, as photographed by a student

Loosened personal-professional boundaries also enabled the students to experience a level of familiarity and interprofessional rapport in the clinical setting, hitherto unknown to them in their urban rotations. "You get a more personal relationship with the staff and the doctors, which may make it easier to discuss patient care or concerns," remarked Lena (student), "so that's an opportunity of working in a rural location." The students perceived an unmistakable contrast with their prior city-based clinical experiences, as Rebecca (student) pointed out: "There was no way that I could get to know the [urban] staff as intimately as I did... here in my preceptorship." This intimacy could occasionally become a liability. "Everyone knows everyone's business," said Tiffany (student). "Someone who worked there [in long-term care]... came into Emergency for something... and everyone knew her. So it's just kind of hard sometimes."

On the positive side, the students felt welcomed and respected by the entire staff. "Within the first week the doctors knew my name," Alissa remarked. "One, he always goes "How are you, Alissa?' and uses my name every time he talks to me. The other one, he calls me Shadow. It's kind of funny." Anna (preceptor) admitted that new graduates' rural experiences were not always so encouraging: "That saying that nurses eat their young... It's very intimidating in some clinical experiences and it can make or break some students... we are just stars in bullying." Conscious of the risk of horizontal violence, Anna used personal connections with her colleagues to ensure her student would feel welcomed. "We have a really good, really warm working environment amongst the nurses... that's a bonus for preceptorship work too, because it makes it easy...to find someone for [Rebecca] to spend time with on my days off." Rebecca elaborated how this environment directly contributed to her clinical skill development. "I probably wouldn't do as well [with other staff] because I'd be so nervous... [but] I've always had something that I 
could learn from everybody... they foster a positive learning environment." Psychosocial support from the entire staff enabled the students to build knowledge, confidence, and team ethos.

\section{Discussion}

Generally speaking, the data (and metadata) corroborate the findings of previous studies on rural preceptorship. Clinical teaching was a challenge willingly undertaken by the preceptors, but they were hard-pressed to spread themselves any more thinly (Bratt, 2009; Keahey, 2008; Shannon et al., 2006). Photovoice data collection, like teaching, was worthwhile insofar as it enabled these nurses to advocate for rural careers and living (Amundson et al., 2008; Charles et al., 2006; Shannon et al., 2006; Yonge, Myrick, \& Ferguson, 2011b). Photovoice discussions also created teachable moments on which to capitalize (Yonge et al., 2006, 2011a), such as an exchange on making do when the air ambulance was grounded. Digital storytelling, on the other hand, clearly did not connote enough value to warrant an additional time commitment. At least one preceptor complained that her existing administrative duties were already detracting from valuable teaching time (Pront et al., 2013; Zournazis \& Marlow, 2015).

The observation of Yonge et al. (2006) that rural students and preceptors are most challenged by isolation, severe weather, and the undersupply of human and material resources was found to be equally valid for suburban and semi-rural sites. Students are well advised to undergo "cognitive and psychological preparation, as well as the acquisition of common advanced clinical skills" (Sedgwick \& Yonge, 2008, p. 625) whether or not their chosen sites are officially "rural." A more nuanced and inclusive set of criteria for rurality, beyond remoteness and population size, may better serve suburban and semi-rural sites both in the nursing curriculum and policy formation. Furthermore, there is no reason to suppose preceptorships at these sites are less likely to pay the dividends of broad clinical coverage, preceptor reflexivity and ongoing education (Charles et al., 2006; Mills et al., 2008; Shannon et al., 2006; Yonge et al., 2013a). For students who desire a comprehensive clinical experience but lack the means to reside in a rural community for an extended period, such sites may represent an ideal compromise.

Unsurprisingly, the participants supplied a number of clinical photos: instruments, supplies, beds, corridors, paperwork, and workstations. While discussions pertaining to challenges tended to center on these concrete aspects of rural practice, participants extended the conversation to a more abstract, relational direction when it came to opportunities. Developing a holistic sense of health, encompassing the community and landscape, was cited repeatedly as a significant outcome by students (Amundson et al., 2008; Charles et al., 2006; Yonge et al., 2013c). At the same time, they alluded to the challenge of serving a rural client base whose community ethos often did not align with professional boundaries and confidentiality (DowdleSimons, 2013; Presley, 2013; Yonge et al., 2013c, 2015). The role modeling of their preceptors, especially regarding reciprocal giving, afforded the students an insight into rural caregiving as a constant balance of professional and community values, in which the rigid maintenance of boundaries was neither sustainable nor desirable (Mills et al., 2007; Yonge et al., 2015).

Rural, clinical settings encouraged the students to develop personal qualities beyond their clinical competencies (Gibb et al., 2004), such as reflexivity, self-assurance, and community mindedness. Freedom from rigid, hierarchical, and siloed professional discourses, to which the students had grown accustomed in their urban rotations, enabled them to reach out to other staff members for their input (Sedgwick, Yonge, \& Myrick, 2009; Sedgwick, 2011; Yonge et al., 2013b), and to feel authentically part of the interprofessional team (Amundsen et al., 2008; 
Charles et al., 2006; MacDowell et al., 2014). The preceptors capitalized on their own, informal relationships with their colleagues to facilitate such interactions (Sedgwick, 2011; Yonge et al., 2013b).

The challenges of the preceptor-student relationship, prominent in other studies, were notably absent in the dataset. Students and preceptors cited numerous boundary crossings between rural caregivers and community, but the professional boundaries between themselves (Yonge, 2007, 2009) were never consciously acknowledged. The participants did recount instances of students acting as de facto team members (Pront et al., 2013; Sedgwick \& Rougeau, 2010; Yonge et al., 2013b) hinting that the students became enmeshed with the staff, although these boundary crossings did not compromise patient safety or undermine the objective of the clinical experience. It is fitting to ask if personal closeness with students made the preceptors' task of evaluation more difficult (Yonge, 2007; Yonge et al., 2011a), or if the seeming invisibility of faculty members was a cause for concern (Luhanga et al., 2010; Sedgwick \& Yonge, 2009; Yonge et al., 2013b).

The study also yielded valuable metafindings: multimedia PAR places considerable demands on the time of participants (such as busy rural nurses), who will agree only to the extent they perceive value in the project output. Photography and other data collection modalities influence the way participants reify their experiences, evincing McLuhan's (1964) famous pronouncement that "the medium is the message because it shapes and controls the scale and form of human association and action" (p. 9). Photography mediated the experiences of participants by inducing them to seek concrete representations of challenges and opportunities, either directly or figuratively. This is a putative strength of photovoice as it enables research participants to exercise creative aptitudes and symbolic thinking (Yonge et al., 2013a). Such thinking, however, may have suppressed the most abstract and psychosocial aspects of preceptorship, such as the student-preceptor relationship. It is evident that these types of phenomena are not easily captured by the lens alone; for all its technological advances, photography remains a convention-bound activity, influencing (as does language itself) the way people construct reality (Harrison, 2002). While this challenge may be mitigated by group discussion in photovoice methodology (Wang \& Burris, 1997), the researchers nonetheless introduce it here as a pertinent metafinding. It is open to speculation how digital storytelling might have further shaped participants' reification of their own experiences, had the digital story initiative played out more substantively.

\section{Conclusion}

In recruiting new nurses and nursing students to sites outside major urban centres, the greatest challenge lies in countering the widespread perception that, in such sites, the difficulties greatly outweigh the rewards. This study has implications for all stakeholders in rural nursingstaff, administrators, educators, students, policymakers, researchers, and the rural client baseinsofar as it illustrates how frontline clinical educators and their students can be powerful advocates both for rural nursing careers and for a greater sense of urgency at the policy level, in addressing the growing crisis of rural health care undersupply. The key to such empowerment, it has been argued, lies in democratizing research through participant action and producing message-driven output that competes for attention in a wired, media-saturated world. This study illustrates the potential of digital technology to revolutionize participant action research, while providing some caveats regarding its potential to overburden or distort the experiences of the very individuals it is intended to empower. 


\section{References}

Amundson, M., Moulton, P., Zimmerman, S., \& Johnson, B. (2008). An innovative approach to student internships on American Indian Reservations. Journal of Interprofessional Care, 22(1), 93-101. https://doi.org/10.1080/13561820701715091

Baum, F., MacDougall, C., \& Smith, D. (2006). Participatory action research. Journal of Epidemiology and Community Health, 60, 854-857. https://doi.org/10.1136/jech.2004.028662

Bratt, M. (2009). Retaining the next generation of nurses: The Wisconsin Nurse Residency Program provides a continuum of support. Journal of Continuing Education in Nursing, 40(9), 416-425. https://doi.org/10.3928/00220124-20090824-05

Charles, G., Bainbridge, L., Copeman-Stewart, K., Art, S., \& Kassam, R. (2006). The interprofessional rural program of British Columbia (IRPbc). Journal of Interprofessional Care, 20(1), 40-50. https://doi.org/10.1080/13561820500498154

Dowdle-Simmons, S. (2013). Educational strategies for rural new graduate registered nurses. Journal of Continuing Education in Nursing, 44(3), 107-110.

https://doi.org/10.3928/00220124-20121217-94

Fenton, G. (2014). Involving a young person in the development of a digital resource in nurse education. Nurse Education in Practice, 14(1), 49-54. https://doi.org/10.1016/j.nepr.2013.04.014

Gazarian, P. (2010). Digital stories: Incorporating narrative pedagogy. Journal of Nursing Education, 49(5), 287-290. https://doi.org/10.3928/01484834-20100115-07

Gibb, H., Anderson, J., \& Forsyth, K. (2004). Developing support for remote nursing education through workplace culture that values learning. Australian Journal of Rural Health, 12(5), 201-205. https://doi.org/10.1111/j.1440-1854.2004.00605.x

Gubrium, A., \& Harper, K. (2013). Participatory visual and digital methods. Walnut Creek, CA: Left Coast Press.

Harrison, B. (2002). Seeing health and illness worlds - using visual methodologies in a sociology of health and illness: A methodological review. Sociology of Health \& Illness, 24(6), 856-872. https://doi.org/10.1111/1467-9566.00322

Keahey, S. (2008). Against the odds: Orienting and retaining rural nurses. Journal for Nurses in Staff Development, 24(2), E15-E20. https://doi.org/10.1097/01.nnd.0000300875.10684.be

Luhanga, F., Dickieson, P., \& Mossey. S. (2010). Preceptor preparation: An investment in the future generation of nurses. International Journal of Nursing Education Scholarship, 7(1). https://doi.org/10.2202/1548-923x.1940

MacDowell, M., Glasser, M., Weidenbacher-Hoper, V., \& Peters, K. (2014). Impact of a rural interprofessional health professions summer preceptorship educational experience on participants' attitudes and knowledge. Education for Health, 27(2), 177-182. https://doi.org/10.4103/1357-6283.143783 
McLuhan, M. (1964). Understanding media: The extensions of man. New York, NY: McGrawHill.

Mills, J., Francis, K., \& Bonner, A. (2007). Live my work: Rural nurses and their multiple perspectives of self. Journal of Advanced Nursing, 59(6), 583-590. https://doi.org/10.1111/j.1365-2648.2007.04350.x

Mills, J., Francis, K., \& Bonner, A. (2008). Walking with another: Rural nurses' experiences of mentoring. Journal of Research in Nursing, 13(1), 23-35. https://doi.org/10.1177/1744987107078907

Otañez, M., \& Guerrero, A. (2015). Digital storytelling and the viral hepatitis project. In A. Gubrium, K. Harper, \& M. Otañez (Eds.). Participatory visual and digital research in action (pp. 57-70). Walnut Creek, CA: Left Coast Press.

Presley, C. (2013). Cultural awareness: Enhancing clinical experiences in rural Appalachia. Nurse Educator, 38(5), 223-226. https://doi.org/10.1097/nne.0b013e3182a0e556

Pront, L., Kelton, M., Munt, R., \& Hutton, A. (2013). Living and learning in a rural environment: A nursing student perspective. Nurse Education Today, 33(3), 281-285. https://doi.org/10.1016/j.nedt.2012.05.026

Sedgwick, M. (2011). Rural hospital interdisciplinary team members' experience of undergraduate nursing preceptorship: A qualitative descriptive study. Nurse Education in Practice, 11(4), 278-282. https://doi.org/10.1016/j.nepr.2011.01.004

Sedgwick, M., \& Rougeau, J. (2010). Points of tension: A qualitative descriptive study of significant events that influence undergraduate nursing students' sense of belonging. Rural \& Remote Health, 10(4), 1-12.

Sedgwick, M., \& Yonge, O. (2008). Undergraduate nursing students' preparedness to 'go rural'. Nurse Education Today, 28(5), 620-626. https://doi.org/10.1016/j.nedt.2007.09.014

Sedgwick, M., \& Yonge, O. (2009). Students' perception of faculty involvement in the rural hospital preceptorship experience. International Journal of Nursing Education Scholarship, 6(1). https://doi.org/10.2202/1548-923x.1833

Sedgwick, M., Yonge, O., \& Myrick, F. (2009). Rural-hospital-based preceptorship: A multidisciplinary approach. Journal for Nurses in Staff Development, 25(5), E1-7. https://doi.org/10.1097/nnd.0b013e3181ba3acb

Shannon, S., Walker-Jeffreys, M., Newbury, J., Cayetano, T., Brown, K., \& Petkov, J. (2006). Rural clinician opinion on being a preceptor. Rural \& Remote Health, 6(1), 1-13.

Van Hofwegen, L., Kirkham, S., \& Harwood, C. (2005) The strength of rural nursing: Implications for undergraduate nursing education. International Journal of Nursing Education Scholarship 2(1). https://doi.org/10.2202/1548-923x.1142

Wang, C., \& Burris, A. (1997). Photovoice: Concept, methodology, and use for participatory needs assessment. Health Education \& Behaviour 24(3), 369-387. https://doi.org/10.1177/109019819702400309 
Wilson, C., \& Flicker, S. (2015). Picturing transactional sex: Ethics, challenges, and possibilities. In A. Gubrium, K. Harper, \& M. Otañez (Eds.). Participatory visual and digital research in action (pp. 73-86). Walnut Creek, CA: Left Coast Press.

Yonge, O. (2007). Preceptorship rural boundaries: Student perspective. Online Journal of Rural Nursing \& Health Care, 7(1), 5-12.

Yonge, O. (2009). Meaning of boundaries to rural preceptors. Online Journal of Rural Nursing \& Health Care, 9(1), 15-22.

Yonge, O., Ferguson, L., \& Myrick, F. (2006). Preceptorship placements in western rural Canadian settings: Perceptions of nursing students and preceptors. Online Journal of Rural Nursing \& Health Care, 6(2).

Yonge, O., Myrick, F., \& Ferguson, L. (2011a). Preceptored students in rural settings want feedback. International Journal of Nursing Education Scholarship, 8(1), 1-14. https://doi.org/10.2202/1548-923x.2047

Yonge, O., Myrick, F., \& Ferguson, L. (2011b). The process of developing a framework to guide rural nurse preceptors in the evaluation of student performance. Nurse Education in Practice, 11(2), 76-80. https://doi.org/10.1016/j.nepr.2011.01.001

Yonge, O., Myrick, F., Ferguson, L., \& Grundy, Q. (2013a). Nursing preceptorship experiences in rural settings: 'I would work here for free'. Nurse Education in Practice, 13(2), 125131. https://doi.org/10.1016/j.nepr.2012.08.001

Yonge, O., Myrick, F., Ferguson, L., \& Grundy, Q. (2013b). 'You have to rely on everyone and they on you': Interdependence and the team-based rural nursing preceptorship. Online Journal of Rural Nursing \& Health Care, 13(1), 4-25.

Yonge, O., Myrick, F., Ferguson, L. \& Grundy, Q. (2013c). Multiple lenses: Rural landscape through the eyes of nurse preceptors and students. Journal of Rural and Community Development, 8(1), 143-159.

Yonge, O., Myrick, F., Ferguson, L. \& Grundy, Q (2015). Lessons about boundaries and reciprocity in rural-based preceptorships. Quality Advancement in Nursing Education, 1(2), 1-12. https://doi.org/10.17483/2368-6669.1002

Zournazis, H., \& Marlow, A. (2015). The use of video conferencing to develop a community of practice for preceptors located in rural and non-traditional placement settings: An evaluation study. Nurse Education in Practice, 15(2), 119-125. https://doi.org/10.1016/j.nepr.2014.11.004 